José Augusto Chaves Guimarães, D. Grant Campbell, Suellen Oliveira Milani, Helber Holland. 2019. Cultural Biases in Knowledge Organization Systems: A Discussion Regarding International University Rankings. NASKO, Vol. 7. pp. 48-62.

José Augusto Chaves Guimarães-São Paulo State University - UNESP, chaves.guimaraes@unesp.br

D. Grant Campbell-University of Western Ontario, gcampbel@uwo.ca Suellen Oliveira Milani-Federal University of Niterói - UFF Rua Lara, suellenmilani@id.uff.br

Helber Holland-São Paulo State University - UNESP, helber.holland@unesp.br

\title{
Cultural Biases in Knowledge Organization Systems: A Discussion Regarding International University Rankings
}

\section{Introduction}

In Library and Information Science it is agreed that knowledge organization systems - KOS are constructed and reviewed in compliance with the values of a certain space, at a certain time, the goals which permeated the institution responsible for them, and the assumptions of the ones involved in the process. In this sense, Guimarães (2017) states that any KOS is slanted by definiton since it is the product of a certains social reality.

Generally, these KOS are constructed under a rationalist and empiricist perspective based on literary, use and terminological warrant (McTavish, Neal and Wathen, 2011). On the other hand, a KOS is the product of historical, cultural, and social factors, whose concepts reflect the divisions of scientific/cultural/social labor in knowledge domains (Albrechtsen and Jacob, 1998; McTavish, Neal and Wathen, 2011). From this perspective, KOS would be understood as political tools for a reliable mediation.

In order to promote an ethical relation towards different professions and their user communities, classification processes in daily activities may be observed. For instance, the classification practice performed by Canadian nutritionists regarding healthy eating reflects and confirms the standards set by Canada's food guide (McTavish, 2015).

In Knowledge Organization, when document surrogates constructed through the application of a KOS convey prejudice, or negative slanting and inclinations, we say that they convey biases. Biases can be harmful to user communities and may produce distortions in subject representation, causing detrimental effects on library users, especially those who do not belong to the dominant communities.

In recent decades, new configurations of KOS have arisen, committed not to representing subjects in documents but to furnishing weighted subject categorizations for evaluation purposes, such as occurs with the international university rankings. The enhancement of scientometric methodologies has made possible the application of business- intelligencebased tools to the organization and analysis of huge amount of data. This scenario has reached, especially in the last decade, the higher education sector, by means of university rankings. Nowadays, those rankings are clearly inserted into the evaluation of the academic performance, "not only on the level of individual researchers, but of entire research centres, departments and even universities (Dehon, Jacobs and Vermandele, 2009, p.2) and one can 
José Augusto Chaves Guimarães, D. Grant Campbell, Suellen Oliveira Milani, Helber Holland. 2019. Cultural Biases in Knowledge Organization Systems: A Discussion Regarding International University Rankings. NASKO, Vol. 7. pp. 48-62.

safely say that they are an inherent phenomenon of the 21 st Century, especially because of their ability to indicate important trends to the university governance(Axel-Berg).

If until some decades ago the universities had their academic reputation and prestige based on their historicity and tradition, nowadays a new and competitive landscape arises, where quantified measures of scientific productivity and visibility are vital to getting a good evaluation in international university rankings. University rankings results are, therefore, considered important sources to the mass media; to universities themselves engaged in selfevaluation, planning, and funding; and also to high school students aiming to make good decisions about the universities available to them (Hongcai, 2009).

The first international university ranking - Academic Rankings of World Universities or simply Shanghai Ranking (ARWU, s.d.) - was created in China, in 2003, in order to respond to a specific demand of the Chinese government for funding purposes.

Because the Shanghai ranking evidenced a preponderance of North American universities, in 2004 the British newspaper Times Higher Education (THE, s.d.; Baty, 2010) published its first global university ranking in an effort to present British universities internationally as World Class learning institutions rather than merely successful domestic ones. In the beginning, this ranking was developed by British universities in partnership with the educational management consultancy firm Quacquarelli Symonds (QS, s.d.), responding to the fact that higher education systems needed a broader assessment (Baty, 2010). In 2009, Quacquarelli Symonds consultancy left Times Higher Education cooperation and created its own ranking with Thomson ISI data and, in 2017, the Centre for Science and Technology Studies da Leiden University (Netherlands) created the CWTS Leiden Ranking (Leiden, s.d.

The four university rankings mentioned above can be considered the most important ones, not only for their comprehensiveness but also for the accuracy of their data and analysis. In this paper, we consider those four university rankings as knowledge organization systems, since all of them present a classificatory scheme composed by a faceted structure of indicators and sub-indicators (which can be considered their subject categories and subcategories) that are applied to the university data in order to get a final classification (subject representation).

As KOSs, they presuppose an analytico-synthetic process, where the subject analysis is based on the evaluation of the university data under each category and subcategory, and the synthesis occurs by means of the application of a weighting process similar to that of some indexing and classification systems (Sparck-Jones, 1973; Salton ; Buckley, 1988; Foskett, 1996; Kang; Lee, 1996; Ren; Sohrab, 2013, among others).

The KOS nature of those rankings is further enhanced by the fact that each indicator and sub-indicator presents specific rules to be applied, similar to the scope notes of thesauri.

As a result of this analytico-synthetic process, the representation of each university within the ranking is evidenced through a position, which can be considered as a kind of subject notation, as a "system of written symbols that can be combined according to some set of syntactical rules to represent various meanings in a specialized domain and can be considered as special languages, for specific purposes" (Sammet \& Tabory, 1968; Gnoli, 2018). 
José Augusto Chaves Guimarães, D. Grant Campbell, Suellen Oliveira Milani, Helber Holland. 2019. Cultural Biases in Knowledge Organization Systems: A Discussion Regarding International University Rankings. NASKO, Vol. 7. pp. 48-62.

Although those rankings are especially useful for the planning and self-evaluation of universities all over the world, they are sometimes used - or interpreted - in a distorted way, focusing uniquely on the results and without considering their historicity, purposes, methodology, and structure - in other words, the contextual bias - that permeate them.

As pointed out by Benoit Millot (2015, p.156):

Ranking entire higher education systems is not an easy task. The multiple functions of such systems, the diversity of their missions, the absence of a consensus on what constitutes the quality of a system, and the lack of universally available, measurable indicators to reflect these functions and missions all make it a daunting enterprise. Given this complexity, attempts at ranking higher education systems are still few.

The complexity of ranking begs the question: to what extent do the structures of the international university rankings, when analyzed from the persepectives of knowledge organization, reveal their cultural biases? If we accept that university rankings are knowledge organization systems, designed and structured according to knowledge organization principles of analytico-synthesis, facet structures and rules of application, we must also face the fact that knowledge organization systems are "[...] permeated by dominant conceptions, paradigms, tendencies, and even prejudices of a time" (Barité, 2001, 50). In their status as KOS artifacts, university rankings are abstract constructions permeated with particular assumptions and, therefore, they are, in Barité's terms, artificial, contingent and determinative (2001, 50). By examining these rankings according to their KOS structural characteristics, we hope to bring these assumptions to light.

Therefore, this paper aims to:

- present university rankings as knowledge organization systems;

- compare the structures from the following rankings: Times, QS, Shangai, and Linden; and

- point out cultural biases which permeate these university rankings.

\section{Knowledge Organization Systems and Cultural Biases}

For research and teaching purposes, KO can be understood in a broader meaning and in a narrower meaning, as attested by Hjørland (2008). It is possible to demonstrate the broader meaning of $\mathrm{KO}$ when it is considered the Classification of beings in Science, which "[...] from Aristotle to our days is of fundamental interest to logicians and scientists related to domains in which classification develops an important role" (Pombo 1988, 2). The knowledge organization articulated by Aristotle, Porfirio and Linnaeus would be considered in this category.

The broader meaning of $\mathrm{KO}$ also involves the Classification of knowing: in other words, the Classification of Science. Such philosophers as Plato, Bacon and Hobbes sought to conceptualize science and its products (Pombo, 1998), and the broader structures and relations of knowledge.

On the other hand, there is a narrower meaning of $\mathrm{KO}$, which deals with the Classification of documents - here understood as registered and socialized information, or Science of Classification, as mentioned by Pombo (1998). Such philosophers and scholars as Calimacus, Gessner, D'Alembert, Diderot, Harris, Dewey, Cutter, Kaiser, Otlet, Bliss and Ranganathan belong in this category. In this context, classification and indexing emerge as core processes. 
José Augusto Chaves Guimarães, D. Grant Campbell, Suellen Oliveira Milani, Helber Holland. 2019. Cultural Biases in Knowledge Organization Systems: A Discussion Regarding International University Rankings. NASKO, Vol. 7. pp. 48-62.

In this narrower meaning, $\mathrm{KO}$ is " $[\ldots]$ concerned with the nature and quality of such knowledge organizing processes (KOP) as well as the knowledge organizing systems (KOS) used to organize documents, document representations, works and concepts" (Hjørland 2008, 86).

By characterizing knowledge as information, $\mathrm{KO}$ systems work as bridges, spanning "[...] cultural, social, national, spatial, temporal, linguistic, and domain boundaries" (Beghtol, 2005, 903); therefore positions and assumptions regarding them should to be clearly stated. While KO systems "[...] represent formal knowledge about concepts" (Soergel 2009, 3), serious confusion can arise from different implicit definitions (Mazzocchi 2019). Some might define "concept" to be something essential and context-free, while others might definite it as something intrinsic to context. Some might define "knowledge" as a mirror of an objective reality, while others define it as something embedded in cultural, historical and theoretical scaffolding.

When classifying or indexing, librarians subject information to "bibliographic control," and this professional activity promotes standardization and representation for the preservation and subsequent retrieval of, and access to, information. At the same time, this process of control restrains information and the potential connections and relationships that could be represented. And because library catalogs, like library collections, are spaces where multiple voices are present, librarians have the unenviable task of negotiating multiple voices and perspectives, and integrating that diversity into a knowledge organization system that is, by nature, non-neutral. The awareness of this paradox-that libraries are non-neutral mediators between multiple voices - forms the core of ethical awareness in knowledge organization. A typical issue in this regard is about cultural biases.

When classification numbers and indexing terms, for instance, convey prejudice, slanting and inclinations, it is understood that they convey biases: assumptions arising from social, cultural and environmental factors that favour some knowledge structures as inevitable, while blocking others. Biases can be harmful to user communities when they reflect unexamined beliefs and assumptions on the part of the professional responsible for classification and indexing, or the body in charge of constructing or maintaining the KO system. These tendencies when they align with the prejudices of a dominant group within the user base, causing detrimental effects on library users, especially those who do not belong to the dominant communities (Milani, 2016).

Cultural biases have been investigated through critical approaches to knowledge organization, approaches which aim to locate ruptures in KO structures, including the systems themselves, and develop or improve techniques and technologies that make the boundaries of our systems permeable (Olson 2001).

According to Fox and Reece (2012), indexers and classifiers apply ethics based on their own moral judgments and when requesting changes to the KO systems they use, for instance, even if such changes involve bureaucratic and often lengthy processes. It turns out that systems and librarians generally "[...] have the same interests, but the imbalanced distribution of power and agency can lead to excesses and abuse of power at the expense of the weaker" (Fox and Reece 2012, 378). 
José Augusto Chaves Guimarães, D. Grant Campbell, Suellen Oliveira Milani, Helber Holland. 2019. Cultural Biases in Knowledge Organization Systems: A Discussion Regarding International University Rankings. NASKO, Vol. 7. pp. 48-62.

This imbalance of power makes the pragmatic understanding of KOS sine qua non; it is necessary to recognize the efforts of the institutions that manage them, but the reflections on these practices must be constantly discussed, especially in their ethical aspects.

Since promoting equity in libraries through their catalogs involves actions to give voice to the different user communities, we need to examine how those voices are heard both within libraries and within the broader academic organizations which create and fund those libraries. The assumptions and presumptions that permeate KO have to be discussed in a narrower perspective (e.g. classification in libraries) as well as in a broader perspective (e.g. academic organization) highlighting the influence of the institutions which support them. And this leads us to the ranking systems that shape the decisions of students and university administrations: systems that are, in their own right, KO systems of complex cultural provenance.

\section{Method}

This study is exploratory and documental, and adopts an inductive method. The research was carried out in three steps: the first one aimed to specifically characterize each university ranking - THE, Shanghai, QS e Leiden - as a socially-situated KOS, by identifying their cultural contexts (producers, sources, objectives); the second step was focused on identifying the subject categories and subcategories and their weights, as well as the composition of the final notation. Finally, and based on the two previous steps, the third one analyzes comparatively the structure and context of the sample of prominent universities in the field of knowledge organization, namely: University College of London, University of Copenhagen, University of Loughborough, University of Sheffield, University of Toronto, and University of Washington. The scores obtained by the mentioned universities in the four rankings in 2018 were compared in terms of categories and subcategories

\section{Shanghai (ARWU) Ranking}

The Shanghai ranking, nowadays known as the Academic Ranking of World Universities (ARWU), was first published in 2003 by the Center for World-Class Universities of Shanghai Jiao Tong University, China, and published year-by-year. Since 2009, it has been published by the Shanghai Ranking Consultancy, which is a fully independent organization on higher education intelligence and not legally subordinated to any universities or government agencies. There is no easy way to define a world class university, or its principal indicators, so AWRU attempts to quantify and measure excellence in order to form strategic goals for Chinese institutions. To minimize problems of interpretation and questions of bias, this ranking was based on open and verifiable institutions' information, and so avoids many of the criticisms levelled at the Times Higher and Quaquarelli Symonds about the lack of transparency and clarity in methodology. The ARWU does not contain a reputational survey so it is not driven by commercial interests. It is therefore considered the most rigorous and objective of the global rankings (Axel-Berg, 2015).

In ARWU, more than 1,500 universities are evaluated, but only the top 500 are ranked. Results are grouped by region or country. This ranking is based on four main areas: quality 
José Augusto Chaves Guimarães, D. Grant Campbell, Suellen Oliveira Milani, Helber Holland. 2019. Cultural Biases in Knowledge Organization Systems: A Discussion Regarding International University Rankings. NASKO, Vol. 7. pp. 48-62.

of education, quality of faculty, research output and per capita performance. There are two more side rankings in Shanghai, ARWU FIELD and ARWU SUBJECT, and both of these side rankings use the same criteria, only with slight modifications in weightings and application.

\section{THE ranking}

The first appearance of the THE ranking occurred in 2004 as a data collection for students' assessment of the world's leading universities on all six continents. However, the success of its predecessor (AWRU) generated a desire among universities to gather information about how they themselves are faring from year to year and in comparison with other similar institutions. In Brazil, for instance, it is common to compare universities in groups related to the type (private, federal or public) or region (State, Latin America). THE has classified its rankings in 4 general categories: world, teaching, subject and regional. All of them derive from World University Ranking, the first and most powerful of THE publications.

In the World Group, there are three rankings: Global, Reputation and Young University rankings. Teaching Rankings are recently created and gather rankings on teaching- related metrics from three different sources: Wall Street Journal/Times Higher Education College Rankings, Japan University Rankings, and Europe Teaching Rankings. In the category Regional Ranking, there are four categories: Emerging Economies University Rankings, Latin America University Rankings, and Asia University Rankings. In the subject category, we find a global ranking that covers eleven large areas of knowledge and research. All these sub- rankings are derived from the World ranking but with special modifications to better reflect its specific characteristics.

One of the most controversial elements of THE is its reputational survey. Despite all problems of interpretation, it is an impressive work to put together more than 20,000 responses. However, a significant amount of data is supplied by the universities themselves. To rest so much importance to data from the university's self-reporting is not good practice, especially nowadays when internet information is not controlled for accuracy, and academic staff groups, most of the time, are focused in a specific subject area and do not have an overview of other universities. Furthermore, because the ranking is valuable to universities that participate and rank well, once the metrics calculation is known, universities have every motivation to game to system and raise their rankings.

\section{QS ranking}

The Quacquarelli Symonds, as previously mentioned, is run by a consulting firm, whose concerns are more related to the commercial side of rankings. As such, their metrics are much less focused on bibliometric performance indicators and much more on reputation and institutional perception. Relying so much on such a questionable indicator has proven to be

a problematic initiative that clearly favours universities with international marketing and profiles. In 2019 edition, QS World ranked 1,000 institutions. 
José Augusto Chaves Guimarães, D. Grant Campbell, Suellen Oliveira Milani, Helber Holland. 2019. Cultural Biases in Knowledge Organization Systems: A Discussion Regarding International University Rankings. NASKO, Vol. 7. pp. 48-62.

As a reputational ranking proposal, the greater the number of rankings, the greater the QS return. Along with worldwide impact and recognition, QS created others rankings:

- QS World University Rankings by Subject;

- QS Higher Education System Strength Rankings;

- QS Best Student Cities;

- QS World University Rankings by Region:

- BRICS (Brazil, Russia, India, China, South Africa);

○ Asia;

- Arab region;

- Latin America;

- EECA (Emerging Europe and Central Asia);

- QS University Rankings by Location: Mainland China, India, Japan, South Korea and Mexico;

- Global MBA Rankings;

- QS Business Masters Rankings; and

- $\quad$ QS Top 50 Under 50

The last named ranking highlights the world's top 50 universities established within the last 50 years, based on the most recent edition of the QS World University Rankings. It is a ranking factory on demand.

Among the indicators, Academic and Employer Reputation are metrics related to QS surveys that collate expert opinions and employer opinions of those institutions from which they source the most competent, innovative, effective graduates. Faculty to Student Ratio is an indirect metric for teaching quality, where a high number of faculty per student is equivalent to a more appropriate learning environment. Citations per Faculty is a performance indicator measure by the total number of citations received by all papers produced by an institution in a five-year period divided by the number of faculty members at that institution. All citations data is sourced using Elsevier's Scopus database. International Faculty and Students is a internationalization measure of an university.

Other QS rankings are derived from these central indicators, but they are calibrated to meet the demand of each ranking.

For the final score calculation, QS normalizes each indicator using z-scores. These normalized scores are scaled down from 100 to 1 , with 100 being the score achieved by the best performing institution.

\section{Leiden ranking (CWTS) ranking}

The Leiden Ranking is the result of the bibliometric research done at the Centre for Science and Technology Studies (CWTS), Leiden University. First published in 2007, it started covering only European Universities, based on the number of publications and a normalized citation ratio (a size-independent, field-normalized average impact). That means that they are using a crown indicator and not a composite index like the others' Rankings. In the 2007 version only 100 European universities were ranked, but the lists published in 2008 
José Augusto Chaves Guimarães, D. Grant Campbell, Suellen Oliveira Milani, Helber Holland. 2019. Cultural Biases in Knowledge Organization Systems: A Discussion Regarding International University Rankings. NASKO, Vol. 7. pp. 48-62.

rank 250 institutions. They provide several rankings; here we consider their orange (" brute force") ranking based on publication counts multiplied by their field-normalized impact (van Raan 1996).

As pointed out before, a possible solution to the methodological problems regarding multiple dimensional indicators, is to restrict a ranking to a single dimension of performance that can be measured in an accurate and reliable way and regardless any kind of university interference. This is the case with Leiden Ranking because it does not attempt to measure all facts related to universities, but instead, its focuses upon research output. Opting for this method, no data is supplied by the universities, which has the beneficial effect of preventing unwarranted interference in the data interpretation. This also avoids biased indicators such as award-winning staff.

The Leiden Ranking provides three types of indicators: indicators of publication output, indicators of citation impact, and indicators of scientific collaboration. Publication output is measured using the number of publications $(\mathrm{P})$ indicator. This indicator is calculated by counting the total number of publications of a university. Publications that have the document type "letter" in WoS do not count as a full publication but count as one-fourth of a publication. Indicators of citation impact are measure as the proportion of a university's publications that, compared with other publications in the same field and in the same year, belong to the top $1 \%$ ( or $5 \%, 10 \%, 50 \%$ ) most frequently cited. Author self citations are excluded. Indicators of scientific collaboration are metrics related to the proportion of a university's publications that have been co-authored with other organizations. This metric can be measured even in relation to the distance between institutions! In almost every case, indicators are calculated using the full counting method.

\section{Results and Discussion}

A first aspect to be considered is the different structure of the four analyzed university rankings, what can be evidenced through their different categories, subcategories and weights, as follows: 
José Augusto Chaves Guimarães, D. Grant Campbell, Suellen Oliveira Milani, Helber Holland. 2019. Cultural Biases in Knowledge Organization Systems: A Discussion Regarding International University Rankings. NASKO, Vol. 7. pp. 48-62.

Table 1. THE World 2019 indicators and weights

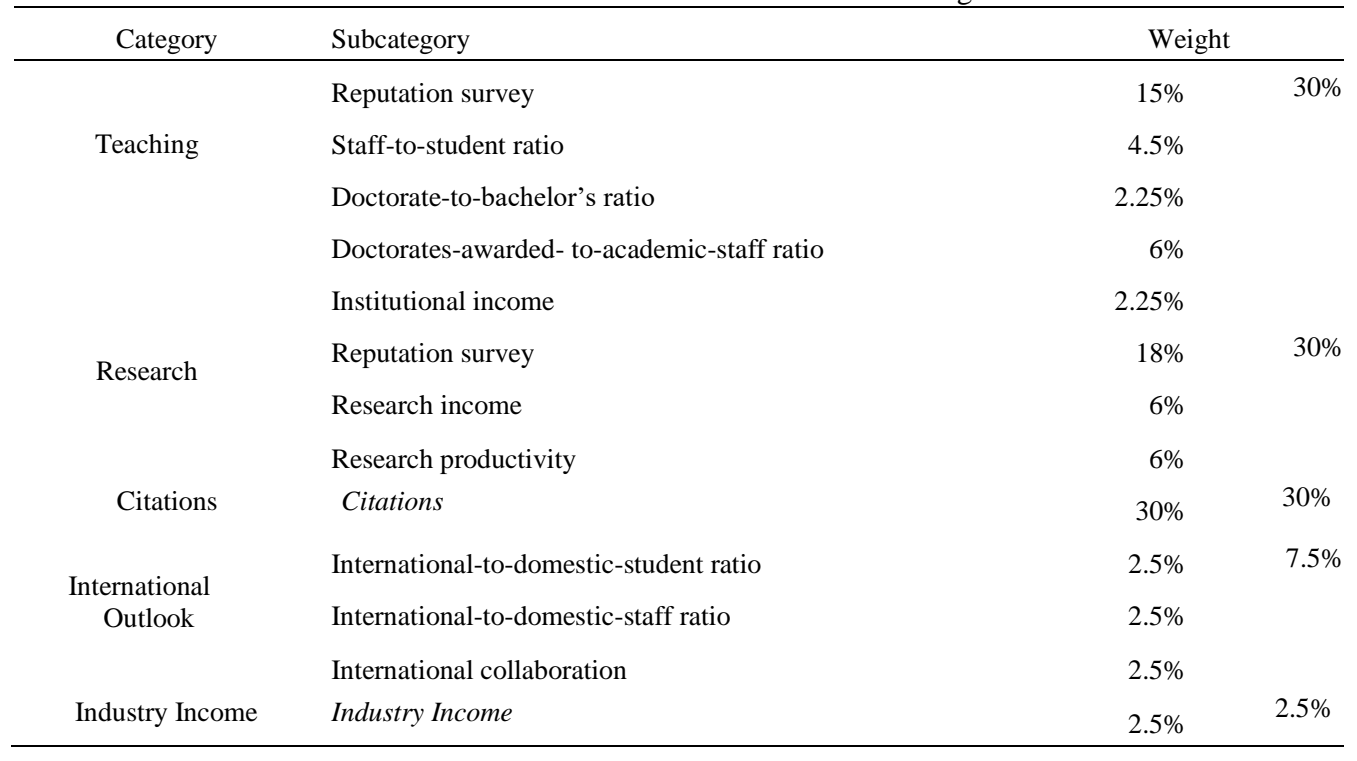

Table 2. AWRU indicators and weights

\begin{tabular}{|c|c|c|}
\hline Category & Subcategory & Weight \\
\hline Quality of Education & Alumni of an institution winning Nobel Prizes and Fields Medals & $10 \%$ \\
\hline \multirow[t]{2}{*}{ Quality of Faculty } & Staff of an institution winning Nobel Prizes and Fields Medals & $20 \%$ \\
\hline & Highly cited researchers in 21 broad subject categories & $20 \%$ \\
\hline \multirow{2}{*}{ Research Output } & Papers published in Nature and Science & $20 \%$ \\
\hline & $\begin{array}{l}\text { Papers indexed in Science Citation Index-expanded and Social Science } \\
\text { Citation Index }\end{array}$ & $20 \%$ \\
\hline $\begin{array}{l}\text { Per Capita } \\
\text { Performance }\end{array}$ & Per capita academic performance of an institution & $10 \%$ \\
\hline
\end{tabular}


José Augusto Chaves Guimarães, D. Grant Campbell, Suellen Oliveira Milani, Helber Holland. 2019. Cultural Biases in Knowledge Organization Systems: A Discussion Regarding International University Rankings. NASKO, Vol. 7. pp. 48-62.

Table 3. QS World 2019 indicators and weights

\begin{tabular}{lcc}
\hline & Category & Weight \\
\hline Academic Reputation & & $40 \%$ \\
Employer Reputation & & $10 \%$ \\
Faculty to Student Ratio & $10 \%$ \\
\hline
\end{tabular}

The Leiden ranking is totally based on bibliometric indicators composed by indicators related to the quantity and quality of the publications, the scientific impact of these publications, the degree of scientific collaboration, and open access, and the final score of one university results from a bibliometric formula considering all those indicators, as it happens in analytic-synthetic KOS as UDC, for instance, where the final notation results from the addition of different facets.

In a comparative analysis, it is possible to observe two natures of university rankings as knowledge organization system. The Shanghai, THE, Shanghai and QS present a typical hierarchical structure with a pre-established set of categories and subcategories as well as weights for all of them. The mentioned hierarchy comprised economic, reputational (based on surveys among academics all over the world) and bibliometric data. On the other side, Leiden ranking can be considered a bibliometric ranking (whose evaluation comprised only the scientific publications and their impact) and presents a typical faceted structure.

The different nature and context of the rankings was a first point for the considerably different representations of the universities. In this sense, it was possible to observe that while THE and QS rankings comprise commercial activities run by private firms, ARWU is operated by a consulting firm and Leiden ranking is conducted by a research group from a public university. Another significant difference was due to the fact that THE, QS and ARWU can be considered "reputational rankings" while Leiden is a typical "bibliometric ranking".

The warrant of the information is also quite different especially in terms of publications and citations, because QS, ARWU and Leiden have their analysis based on Web of Science while THE is based on Scopus. Those two data bases have different coverages and areas of focus.

The category "reputation" in THE, ARWU and QS is strongly subjective and varies substantially from ranking to ranking. ARWU reveals a deep focus on "hard sciences" since it has a special category for prizes (here understood only Nobel Prizes and Fields Medals) as well as another one for papers published in Nature and Science. And those categories, together, respond to $40 \%$ of the final score.

Considering the diversity of those KOS, we analyzed the way these KOS represented, in the 2018 rankings, 6 universities with a deep international research level in the KO field, as follows. 
José Augusto Chaves Guimarães, D. Grant Campbell, Suellen Oliveira Milani, Helber Holland. 2019. Cultural Biases in Knowledge Organization Systems: A Discussion Regarding International University Rankings. NASKO, Vol. 7. pp. 48-62.

Table 4. Similar Universities compared in different rankings

\begin{tabular}{lrrrrr}
\hline \multicolumn{1}{c}{ University } & THE & QS & ARWU & Leiden \\
& World & & World & World & \\
\hline University College of London (UK) & & 14 & 10 & 17 & 15 \\
University of Toronto (Canada) & 21 & 28 & 23 & 2 \\
University of Washington (USA) & 28 & 66 & 14 & 14 \\
University of Sheffield (UK) & 106 & 75 & $101-150$ & 167 \\
University of Copenhagen (Denmark) & 116 & 75 & $101-150$ & 167 \\
\hline
\end{tabular}

The table above shows us three important features of university rankings, when considered as knowledge organization systems. First, as any good indexer knows, it is crucial to keep extension in mind when interpreting the data. The six universities displayed all have strong reputations in the field of knowledge organization; but all four rankings are for the university as a whole, rather than for an individual school, faculty or department. To rank University of Toronto as second and the University of Loughborough is meaningless when considering the strength of a university within a specific field. Rankings of this type are the equivalent of document indexing, in which the terms are co-extensive with the document subject; very often, users of ranking system require the equivalent of depth indexing, extracting subsets of data of specific relevance.

Second, the "knowledge representation" (the ranking score) of the same "subjects" (the universities) differs completely from one "KOS" (ranking system) to another. A good example for that is the University of Toronto, which holds the second world position in Leiden Ranking (as a top scientific publication environment) and the twenty-eighth position in the QS ranking. The differences arise from the different choices of data to collect, and the different weights given to each data category. These choices and weights embody and reflect various cultural biases. The QS and THE rankings, for example, place great weight upon "Academic Reputation," which, in addition to being highly subjective, depends on survey data that can vary both in response rate and from one ranking system to another. The rankings can also vary in terms of coverage, since they present different criteria to include or not a certain university into their evaluation. The rankings work on very different principles of warrant; some rely on university-supplied data about various factors supposed to be relevant to education and research; some rely on survey data; and others, like the Leiden ranking, rely solely on bibliometric indicators.

Indeed, the motivation for the rankings in each case represents a cultural bias. Rankings have historically been used for purposes of promoting and inculcating a sense of pride. The Shanghai ranking came about because China wished to promote its own universities, and the THE system arose from an initial desire to raise the profile of British universities. Ranking in itself implies competition, and the choice of warrant for the ranking is a deeply cultural, political and social choice.

Finally, every knowledge organization system of any value implicitly acknowledges its own limitations. What one system collocates, another separates; libraries have historically 
José Augusto Chaves Guimarães, D. Grant Campbell, Suellen Oliveira Milani, Helber Holland. 2019. Cultural Biases in Knowledge Organization Systems: A Discussion Regarding International University Rankings. NASKO, Vol. 7. pp. 48-62.

used multiple systems, such as subject headings and classification, in the assumption that one system will compensate for the defects of the other. In the same way, users of ranking systems must be aware that no metrics, however rigorous, can completely capture the ephemeral qualities of an educational experience. As Cathy O'Neil has indicated, big data systems work through the establishment of proxies: to measure something subjective, we find a quantifiable variable that correlates, positively or negatively, with the elusive variable we really care about $(2016,17)$. We cannot measure the quality of teaching directly, but we can select a measurable quality, such as the teacher-student ratio, as a stand-in.

Ranking systems can make intelligent and sensible decisions about the proxies they use to measure the complexity of university life and university achievement. But ultimately, many of these rankings depend on correlations that have only limited application.

\section{Conclusions}

Considering that international university rankings are very often used as a marketing tool for universities to show their educational or research excellence and that they are substantively influencing the decision-making and planning processes within higher education institutions around the world, the research demonstrated that those rankings are an emerging format of KOS and have more and more social and scientific impact.

Nevertheless, those rankings cannot be used or consulted without considering their contexts and their cultural slants, because each of them represents a domains as "a unit of analysis for the construction of a KOS" and, in this condition, it reflects "a group with an ontological basis that reveals an underlying teleology, a set of common hypotheses, epistemological consensus or methodological approaches, and social semantics" (Smiraglia, 2012, p.114). Domains are located in space and time and, as a consequence, are dynamic. So, the subject categories and subcategories (indicators and sun-indicators) of those rankings are subject of constant change in accordance to a wide range of economic, political, social and cultural interests. This allow us to state that, as it occurs to specialized classifications or thesauri, each rankings is more suitable to represent a certain kind of university because its slants are more able to represent the specificity of that educational context.

This is not to say that we should avoid rankings, or that we shouldn't appreciate their considerable achievements in collecting, collating and representing enormously complex data in ways that assist decision-making. But as knowledge organization systems, they reveal the same paradox that plagues all knowledge organization systems: they try to do the impossible, and they are admirable for their partial success, rather than their complete mastery. Knowledge organization has always worked with an awareness of the limits of its tools and paradigms, and that awareness is perhaps the greatest contribution it can make to the challenge of using and interpreting university rankings.

\section{References}

Axel-Berg, J.H. 2015. "COMPETING ON THE WORLD STAGE: the Universidade de São Paulo and Global Universities Rankings”. São Paulo : USP (MSc Thesis). 
José Augusto Chaves Guimarães, D. Grant Campbell, Suellen Oliveira Milani, Helber Holland. 2019. Cultural Biases in Knowledge Organization Systems: A Discussion Regarding International University Rankings. NASKO, Vol. 7. pp. 48-62.

Axel-Berg, J. 2018. Indicadores para efeito de comparação internacional no ensino superior brasileiro. In: Marcovitch, Jacques (org.) Repensar a universidade: desempenho acadêmico e comparações internacionais (Rethinking the university: academic performance and international comparisons). São Paulo: ComArte; Fapesp, 2018, pp.31-44.

ARWU. Academic Ranking of World Universities. Available at: http://www.shanghairanking.com/ARWU-Methodology-2018.html>.

Barité, M. 2001. "Organización del conocimiento: un nuevo marco teórico-conceptual en Bibliotecología y Documentación" (Knowledge organization: a new theoretical and conceptual framework in LIS). In: Carrara, K. (ed.) Educação, universidade e pesquisa (Education, university and research), Marília: UNESP, pp.35-60.

Baty, P. "THE World University Rankings". The Times Higher Education Supplement, 2010.

Beghtol, C. 2005. Ethical decision-making for knowledge representation and organization systems for global use. Journal of the American Society for Information Science and Technology 56: 903-12

Dehon, C., D. Jacobs, and C. Vermandele. (2009). Rankings and research assessment in higher education: current and future challenges. In: Ranking universities. Bruxelles: Ed. de l'Ùniversité Libre de Bruxelles, 2009, p.1-11.

Foskett, A.C. 1996. The subject approach to information. 5.ed. London : Facet, 1996.

Fox, M.J. and A. Reece. (2012). Which ethics? Whose morality?: An analysis of ethical standards for information organization. Knowledge Organization 39: 377-83.

Gnoli, C. 2018. Notation. Knowledge Organization 45(8): 667-684.

Guimaraes, J.A.C. 2017. Slanted knowledge organization as a new ethical perspective.. In: Andersen, J.; Skouvig, L. (Org.). The organization of knowledge: caught between global structures and local meaning. Bingley: Emerald, p. 87-102

Hjørland, B. 2008. What is knowledge organization (KO)? Knowledge Organization 35: 86-101.

Hongcai, W. 2009. University rankings: status quo, dilemas, and prospects. Chinese education and society $42(1): 42-55$

Jeremic, V., M. Bulajic, M. Martic, Z. Radojicic. 2011. A fresh approach to evaluating the academic ranking of world universities. 87; 587-596

Kang, S.; S. Lee. 2005. Document indexing: a concept-based approach to term weight estimation. Information Processing and Management 41(5):1065-1080

Leiden Ranking. Available at: <http://www.leidenranking.com/information/>

Marcovitch, J. (org.). 2018. Repensar a universidade: desempenho acadêmico e comparações internacionais (Rethinking the university: academic performance and international comparisons). São Paulo: Com-Arte; Fapesp.

Mazzocchi, Fulvio. (s.d.). Knowledge Organization System. In: Encyclopedia of Knowledge Organization. www.isko.org/cyclo/kos

McTavish, J. R., D.R. Neal, C.N. Wathen. 2011. Is what you see what you get? Medical subject headings and their organizing work in the violence against women research literature. Knowledge Organization 38(5): 381-97

McTavish, J. 2015. The ethics of querying and permeating Canadian everyday life nutritional classification technologies and processes. Knowledge Organization 42(5): 308-15

Milani, S.O. 2016. Uma discussão de oposições binárias nos Functional Requirements for Subject Authority Data - FRSAD (Binary oppositions in the Functional Requirements for Subject Authority Data - FRSAD). Perspectivas em Ciência da Informação 22: 29-53

Millot, B. 2015. International rankings: Universities vs. higher education systems. International Journal of Educational Development 40: 156-165 
José Augusto Chaves Guimarães, D. Grant Campbell, Suellen Oliveira Milani, Helber Holland. 2019. Cultural Biases in Knowledge Organization Systems: A Discussion Regarding International University Rankings. NASKO, Vol. 7. pp. 48-62.

O’Neil, C. 2016. Weapons of math destruction: How big data increases inequality and threatens democracy. New York: Crown.

Olson, H.A. 2001. Patriarchal structures of subject access and subversive techniques for change. Canadian Journal for Information and Library Science 26:1-29

Pombo, O. 1998. Da classificação dos seres à classificação dos sabers. Leituras: Revista da Biblioteca Nacional de Lisboa 2:19-33

QS Top Universities. 2013. Available at: https://www.topuniversities.com/university-rankings

Ren, F. and Sohrab, M.G. 2013. Class-indexing-based term weighting for automatic text classification. Information Sciences 236: 109-125

Salton, G.; Buckley, C. 1988. Term-weighting approaches in automatic text retrieval. Information Processing and Management: 24: 513-523

Sammet, J.E. and R. Tabory. 1968. Artificial languages. In: Encyclopedia of library and informations science, eds. A. Kent and H. Lancour, New York : Dekker, pp. 632-657

Santos, S.M. 2018. Rankings internacionais de universidades: comparação e desempenho por áreas (International university rankings: comparison and performance among subject fields). In: Repensar a universidade: desempenho acadêmico e comparações internacionais (Rethinking the university: academic performance and intenrational comparisons). org. J. Marcovitch, São Paulo : ComArte; Fapesp, pp.63-92

Smiraglia, Richard P. (2012). Epistemology of domain analysis. In: Smiraglia, R.P.; Lee, H.-L. (ed.) Cultural frames of knowledge. Würzburg ; Ergon. p. 111-124.

Soergel, Dagobert. (2009). Knowledge Organization Systems: Overview. www.dsoergel.com/SoergelKOSOverview.pdf

Sparck- Jones, K.(1973). Index term weighting. Information Storage and Retrieval, 9, pp. 619-633.

THE World University Rankings. Available at: https://www.timeshighereducation.com/worlduniversity-rankings

\section{Referees'comments:}

- the structural analysis and characterization of university ranking systems as a form of KOS that can be broadly analyzed in terms of facet analysis. As presented in the proposal, this analysis is persuasive and potentially offers up new vistas of research into other sorts of ranking systems: for example, one might consider athletic leagues or, perhaps even more on point, fantasy athletic leagues as comparable types of rank-based systems that likewise have classificatory categories (e.g., league divisions) and a faceted structure of indicators, even if they lack notations. The identification of ranking systems as a form of KOS is, in itself, a major contribution to the discourse of $\mathrm{KO}$ and should be expanded in the final paper: for example, it would be good to give examples of faceted indicators and how they are articulated into sub-indicators.

- to what degree, given the different national points of origins of the different ranking systems, the rankings of the sample of KO programs in each system reflect different national educational expectations?.

- the reviewer looks forward to seeing which dimensions of bias are included in the comparative table promised at the end of Section 3. 
José Augusto Chaves Guimarães, D. Grant Campbell, Suellen Oliveira Milani, Helber Holland. 2019. Cultural Biases in Knowledge Organization Systems: A Discussion Regarding International University Rankings. NASKO, Vol. 7. pp. 48-62.

- the group of "university ranking systems" in itself constitutes a domain

- Some clarity could be used in the first paragraph of the introduction and a stronger conclusion 